\title{
El Archivo Histórico del Instituto Nacional de Migración
}

\author{
Pablo Yankelevich y Paola Chenillo Alazraki
}

\begin{abstract}
El artículo pasa revista al proceso de rescate de lo que hoy conforma el Archivo Histórico del Instituto Nacional de Migración. Se analiza el proceso legislativo que hizo posible ese rescate, así como las dificultades de orden jurídico y administrativo que han determinado que ese archivo aún no se haya abierto a la consulta académica. Por otra parte, se analizan las características de las fuentes documentales explicando el sentido del ordenamiento temático y, finalmente, se esboza una agenda de investigación atenta a un ancho universo documental que permitirá redimensionar los estudios sobre la historia de la migración en México.
\end{abstract}

PALABRAS CLAVE: inmigración, emigración, México, archivo, siglo XX

\section{The National Institute of Migration's Historical Archive}

This paper examines the process undergone in order to preserve what is known today as the Historical Archive of the National Institute of Migration. It studies the legislative process that enabled the Archive's restoration, as well as the legal and administrative obstacles that have hampered its availability for academic research. It also analyzes the characteristics of the documental sources and explains their thematic classification. Finally, it outlines a research agenda focused on a broad universe of sources that will allow a reexamination of the history of migration in Mexico.

KEY WORDS: immigration, emigration, Mexico, archive, 20th century

PABLO YANKELEVICH: Instituto Nacional de Antropología e Historia, México-Distrito Federal. py1987@yahoo.com.mx

PaOla Chenillo AlazRAKI: Universidad Nacional Autónoma de México, México-Distrito Federal. paolachenillo@yahoo.com.mx 
$\mathrm{E}$ n abril de 2002 fue aprobada la Ley Federal de Transparencia y Acceso a la Información Pública Gubernamental (LFTAIPG). Esta legislación, ideada con el fin de "garantizar el acceso de toda persona a la información en posesión de los Poderes de la Unión, los órganos constitucionales autónomos o con autonomía local, y cualquier otra entidad federal"1, apuntó a hacer transparente la gestión pública y favorecer la rendición de cuentas en tanto prácticas indispensables en la construcción de un orden democrático. Animados por estas preocupaciones, los legisladores no consideraron las implicaciones que esta ley tendría en materia de conocimiento histórico, aunque de manera general se esbozó la necesidad de organizar los documentos y proteger los datos en ellos contenidos ${ }^{2}$.

La nueva legislación estableció las normas que los ciudadanos debían seguir para solicitar información oficial, así como los procedimientos para que las instituciones oficiales dieran respuesta a las demandas ciudadanas. Sin embargo, la materia que esta ley reglamentó se ubica en la lábil frontera entre la necesaria transparencia, el buen la vida privada. En atención a ello, la legislación instituyó algunas excepciones. En primer lugar, se consideró clasificar cierta información como "reservada" y bajo este calificativo quedarían todos los datos que pondrían en riesgo la seguridad del Estado. Esta información quedaría fuera del dominio público por cierto tiempo hasta que, a juicio de las autoridades correspondientes, se procedería a desclasificarla ${ }^{3}$. En segundo lugar, se estableció que cierta documentación, por contener datos personales, se clasificaría de manera permanente como confidencial, salvo que los titulares de esos datos otorgaran el consentimiento expreso para su divulgación. Es importante señalar que en esta categoría se incluyó una extensa gama

\footnotetext{
${ }^{1}$ Artículo $1^{\circ}$ de la Ley Federal de Transparencia y Acceso a la Información Pública Gubernamental (LFTAIPG), en <http://www.ifai.org.mx/ transparencia/LFTAIPG.pdf $>$.

2 Artículo $4^{\circ}$ de la LFTAIPG, ibid.

${ }^{3}$ El tiempo máximo señalado por la LFTAIPG es de doce años, pero se contempla que, de manera excepcional, las dependencias podrán solicitar la ampliación del tiempo de reserva, siempre y cuando justifiquen que permanecen las causas que dieron origen a su clasificación (artículo $15^{\circ}$ de la LFTAIPG, op. cit.).
}

de asuntos: desde domicilio, patrimonio y características físicas, hasta cuestiones de salud, creencias religiosas, convicciones filosóficas y preferencias sexuales 4 .

Si bien desde un punto de vista político la LFTAIPG ha tenido una enorme relevancia, en el campo de la investigación histórica los resultados han sido contrastantes. Por ejemplo, ha obligado a la reorganización de los archivos de las dependencias públicas, ha obligado a la elaboración de inventarios y guías de consulta respetando normas que garantizan la conservación de los acervos, al tiempo que ha reducido el periodo de reserva de los expedientes que podrían poner en riesgo la seguridad nacional. Pero al mismo tiempo, esta legislación ha dejado fuera del alcance de los investigadores expedientes que contienen datos personales, inclusive aquellos que el mismo titular declaró al realizar un trámite oficial. Una visión estrecha sobre la "privacidad de la información” terminó clasificando como privados datos que, por su propia naturaleza, podrían ser públicos.

Por otra parte, la LFTAIPG reconoce tres tipos de archivos — de trámite, de concentraciones e históricosin establecer ninguna diferencia en cuanto al acceso de la información en cualquiera de estos tres archivos. En agosto de 2003 se publicaron los "Lineamientos generales para la clasificación y desclasificación de la información de los archivos federales"5, y en enero de 2004 se expidieron los "Lineamientos para la organización y conservación de los archivos públicos federales”, sin que estas normativas precisaran mecanismos específicos para el manejo de fondos documentales de carácter histórico ${ }^{6}$. En realidad, este proceso ha puesto de manifiesto la urgencia de que México tenga una ley de archivos que norme la declaratoria y el carácter histórico de documentos gubernamentales y que defina para esos documentos la necesidad y vigencia de proteger los datos que atenten contra la vida privada de las personas?

\footnotetext{
${ }^{4}$ Artículo $2^{\circ}$ de la LFTAIPG, op. cit.

${ }^{5}$ Diario Oficial de la Federación, 18 de agosto de 2003, México-Distrito Federal, en $<\mathrm{http}: / /$ www.ifai.org.mx/informe/Lineamiento6.pdf $>$. ${ }^{6}$ Diario Oficial de la Federación, 20 de febrero de 2004, México-Distrito Federal, en <http://www.ifai.org.mx/informe/Lineamiento7.pdf >. ${ }^{7} \mathrm{Al}$ respecto, César Camacho Quiroz, entonces senador de la Repúbli-
} 


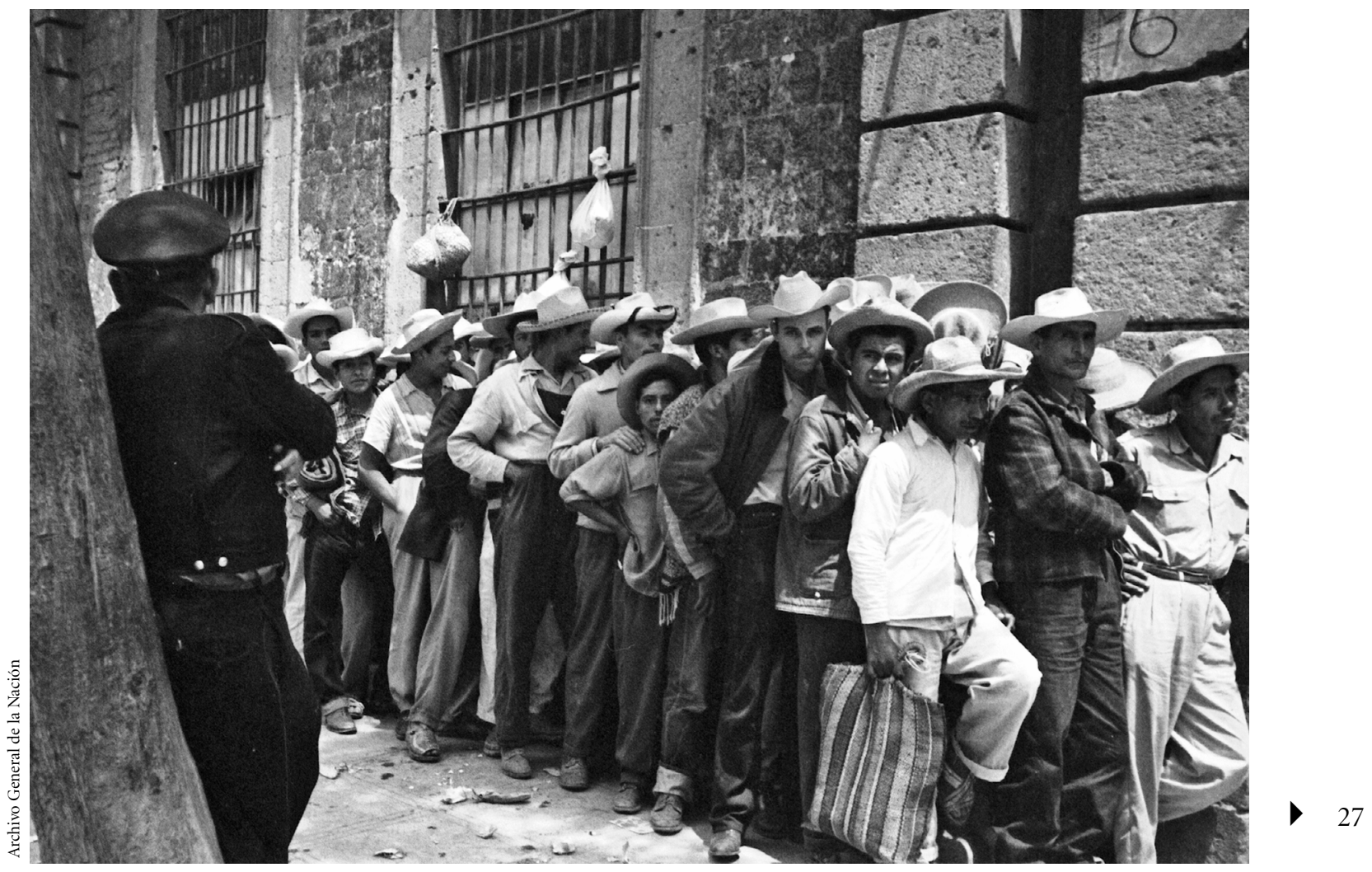

Fila de aspirantes a braceros, La Ciudadela, México, D.F., c. 1945. Sección concentrada, "Braceros", AGN.

En este contexto, las dependencias gubernamentales que ya tenían un archivo histórico no sufrieron mayores cambios, toda vez que estos archivos continuaron funcionando de acuerdo con normas y criterios anteriores a la LFTAIPG. Sin embargo, aquellas dependencias que constituyeron sus archivos históricos a partir de la promulgación de la LFTAIPG se enfrentaron al dilema de definir

ca, presentó, en marzo de 2005, una iniciativa para la promulgación de una Ley Federal de Archivos. Este proyecto generó un intenso debate entre historiadores y archivistas que puede consultarse en H-México: $<$ http://www.h-mexico.unam.mx/foro/entrar.html?numforo= 100014>. El mismo Camacho Quiroz, hoy diputado federal, presentó en septiembre de 2006 un nuevo proyecto que todavía no ha sido motivo de trabajo legislativo ("Iniciativa que expide la Ley Federal de Archivos y reforma al artículo 27 de la Ley Orgánica de la Administración Pública Federal, a cargo del diputado, del Grupo Parlamentario del PRI", Gaceta Parlamentaria, 12 de septiembre de 2006, en <http: //gaceta. diputados. gob.mx/>). desde qué fecha y por qué motivos un documento debía ser considerado como histórico, además del problema de la confidencialidad de la información que contuviera datos personales.

Este fue el caso del Instituto Nacional de Migración (INM). En 2001, cuando los proyectos de la futura LFTAIPG eran motivo de debates legislativos, las autoridades del INM echaron a andar un ambicioso proyecto de rescate y organización de su acervo documental, almacenado en dos edificios en la ciudad de México y en varios del interior de la República. La dispersión de esa documentación y las malas condiciones de las edificaciones atentaban contra la conservación de los documentos, pero además, entorpecían la resolución de los trámites administrativos ${ }^{8}$.

${ }^{8}$ De acuerdo con el diagnóstico que elaboró el propio INM, la mayoría de los inmuebles se encontraban expuestos a incendios, inundaciones 
Ante esta situación se procedió a elaborar un diagnóstico a nivel nacional que culminó en marzo de 2002, y que reveló que los archivos del INM contenían aproximadamente 2400000 expedientes, de los cuales cerca de 85\% pertenecía a las oficinas centrales y el resto a las delegaciones regionales. La documentación se encontraba dividida en dos grandes grupos, bajo los nombres genéricos de Archivo de Trámite y Archivo de Concentración; a este último correspondía una sección conocida como "Archivo Muerto".

Una vez aprobada la LFTAIPG, y tal como ésta lo contempla, se trabajó con la asesoría del Archivo General de la Nación con el fin de normar algunos criterios de organización archivística9 ${ }^{9}$. En junio de 2002 se concluyó un documento que contenía distintas recomendaciones, entre las que destacaba la pertinencia de constituir tres archivos: el de Trámite, para resguardar los expedientes activos generados entre 1985 y la actualidad; el Archivo de Concentración, que almacenaría los expedientes semiactivos fechados entre la actualidad y 1965, y el Archivo Histórico, que concentraría toda la documentación
En diciembre de 2002, el INM adquirió un inmueble en la ciudad de México capaz de albergar en condiciones óptimas todos los expedientes de los distintos archivos centrales, además de los acervos históricos de las delegaciones regionales. Un área especial de aquel edificio fue dedicada al Archivo Histórico, donde se depositaron más de 4000 cajas del hasta entonces "Archivo Muerto". A lo largo de cuatro años se trabajó en el rescate y ordena-

o derrumbes, carecían de mobiliario, de iluminación y de ventilación adecuada. Este diagnóstico se encuentra en el Libro Blanco Modernización del Archivo Migratorio, que se puede consultar en la siguiente dirección electrónica: <http://www.inami.gob.mx/paginas/LibBlancos. htm>.

${ }^{9}$ La Ley de Transparencia determinó que correspondía al Archivo General de la Nación elaborar, en coordinación con el IFAI, los criterios para la catalogación, clasificación y conservación de los documentos administrativos, así como la organización de archivos de las dependencias y entidades (artículo $32^{\circ}$ de la LFTAIPG, op. cit.).

${ }^{10}$ Archivo General de la Nación, "Implementación del sistema integral de administración de documentos y de archivos, migratorio y administrativo, del Instituto Nacional de Migración", 3 de junio de 2002. Este documento se puede consultar en el Libro Blanco Modernización del Archivo Migratorio, op. cit. miento de millares de expedientes hasta reconstruir las series temáticas de aquel enorme universo documental. Esta tarea coronó con la completa digitalización del Archivo Histórico, junto a la total limpieza y reencuadernación de los expedientes.

Este moderno repositorio documental aún no está abierto a la consulta pública, debido a que en el Catálogo de disposición documental del INM quedó establecido que todos los expedientes bajo resguardo de la Coordinación de Regulación Migratoria —entre los que se encuentran los del Archivo Histórico- contenían información confidencial, en el entendido de que buena parte de los expedientes resguardan datos personales ${ }^{11}$.

En el caso de este archivo, la aplicación de la LFTAIPG produjo una auténtica paradoja. Gracias a esa ley fue posible el rescate al que aludimos, pero debilidades de esa misma legislación, aunadas a la ausencia de una norma federal que regule el funcionamiento de los archivos históricos, impiden la consulta de estos expedientes. Las nuevas autoridades del INM están conscientes de esta situación, y en tal sentido han iniciado consultas ante el Instituto Federal de Acceso a la Información para evaluar la posibilidad de desclasificar este archivo, a los fines de abrirlo a la consulta de los académicos interesados en la historia de la migración en México.

\section{LA IMPORTANCIA DEL ARCHIVO}

Algunos fondos documentales del Archivo General de la Nación, del Archivo Histórico Diplomático de la Secretaría de Relaciones Exteriores y del Archivo Histórico de la Secretaría de Salud constituían las únicas referencias en la investigación histórica sobre los fenómenos migratorios ${ }^{12}$. México carecía de un archivo especializado que

\footnotetext{
11 "Primer Informe del Programa de Rendición de Cuentas, diciembre de 2000 a diciembre de 2005", en: <http://www.inami.gob.mx/paginas /rendiciondecuentas/Primer\%20Informe\%20de\%20Rendición\%20d e\%20Cuentas.pdf>; "Catálogo de disposición documental 2007", en: $<$ http://www.inm.gob.mx/paginas/art7/guiasimple/CATALOGO $\% 20$ DE $\% 20$ DISPOSICI\%C3\% 93N\%20DOCUMENTAL \% 202007.pdf>.

12 Es importante destacar que, a consecuencia del sismo de 1985, la Se-
} 
permitiera profundizar en la naturaleza y características de los flujos poblacionales desde y hacia México, así como indagar sobre el diseño y puesta en marcha de las políticas migratorias del Estado mexicano. Esta ausencia de fuentes documentales imprimió un particular sentido a los estudios migratorios. Una rápida mirada a la historiografía permite advertir que un buen número de investigaciones han privilegiado asuntos referidos a inversiones económicas e intercambios mercantiles, subrayando el carácter empresarial de ciertas comunidades extranjeras, junto a aristas políticas y diplomáticas, a manera de grupos de presión ante las distintas políticas nacionalistas implementadas a partir del estallido de la Revolución de 1910. No abundan los trabajos que rescaten los factores cuantitativos de esas colectividades de migrantes ${ }^{13}$ y son aún más escasas las investigaciones dedicadas a las coordenadas cualitativas de la presencia extranjera, esto es, el significado de los flujos poblacionales en sus dimensiones demográficas, sociales, étnicas y culturales ${ }^{14}$.

A lo largo del siglo XX, representantes de más de cuarenta nacionalidades han migrado a México; sin embargo, sólo unas cuantas de esas colectividades han sido objeto de estudio. Los españoles ocupan un lugar privilegiado y constituyen la comunidad con mayor presencia en la historiografía sobre extranjeros en México ${ }^{15}$, seguidos muy lejos por estudios sobre la presencia de chinos, libaneses, franceses y judíos ${ }^{16}$.

El panorama es más desolador en materia de estudios históricos sobre los mexicanos que se dirigieron a Estados Unidos a lo largo de la primera mitad del siglo XX.

cretaría de Gobernación, por la destrucción que sufrieron algunos de sus edificios, transfirió al Archivo General de la Nación uno de los fondos de lo que hoy constituye el Archivo Histórico del INM. Se trató de aproximadamente 200000 tarjetas de identificación de extranjeros residentes en México entre 1926 y 1950. Este fondo se conoce como "Registro de Extranjeros" y está integrado por los originales de las formas migratorias (F14) en los que están asentados los datos personales y de filiación de los inmigrantes extranjeros.

${ }^{13}$ En este sentido destacan los trabajos pioneros de González Navarro, 1974, 1993-1994.

${ }^{14}$ Entre otras obras véase Bonfil Batalla, 1993; Gleizer Salzman, 2000; Gómez Izquierdo, 1991; Puig Llano, 1992; Salazar, 2006.

15 Véase Lida, 2006.

16 Entre otras obras destacan: Hu-Dehart, 1980; Páes Oropeza, 1984; Pérez Siller y Cramaussel, 2004; De Backal, 1993.
Los trabajos pioneros de Manuel Gamio (1969) y Moisés Gonzalez Navarro (1954) han encontrado pocos seguidores en la moderna historiografía mexicana ${ }^{17}$, situación que contrasta con la expansiva presencia de los llamados Chicano Studies en los medios académicos estadounidenses.

Por otra parte, el diseño de políticas migratorias, la constitución de agencias gubernamentales para la atención de estos asuntos y el reclutamiento de personal responsable de la ejecución de aquellas políticas constituye un territorio prácticamente inexplorado por los historiadores. Se carecía de fuentes documentales capaces de echar luz sobre los procesos de toma de decisión en materia de flujos poblacionales.

De cara a este panorama, los fondos contenidos en el Archivo Histórico del INM (AHINM) abrirán nuevas perspectivas en el estudio de viejos temas y plantearán nuevos desafíos en el abordaje de los problemas derivados de la historia de la política migratoria de México. Sobre algunos de estos temas y problemas abundaremos en este artículo, sin más objetivo que exhibir algunas de las posibles líneas de investigación que el AHINM pondrá a disposición de los académicos.

\section{LA NATURALEZA DE LOS DOCUMENTOS}

Se trata de un archivo institucional cuyo origen se remonta a mediados de la década de 1920, cuando los gobiernos emanados de la Revolución sometieron al país y a sus instituciones a un profundo proceso de reorganización, con el fin de dar respuesta a problemas sociales, políticos y económicos expresados a lo largo de la contienda armada. En aquella década se pusieron las bases de una política de población, y en la búsqueda de soluciones se trabajó en la construcción de un marco legal e institucional que cristalizó en 1926 con la creación del Departamento Migratorio, instancia que constituye el antecedente más lejano del actual INM.

\footnotetext{
${ }^{17}$ Véase Carreras de Velasco, 1974; Guerin-González, 1994; Balderrama y Gutiérrez, 1995; Alanis Enciso, 2007.
} 
El casi medio millón de expedientes que custodia el AHINM conforma una herramienta de invaluable importancia para dar cuenta de la historia de la migración en México. En más de un centenar de series temáticas ${ }^{18}$ se reúnen documentos referidos a los movimientos de población, tanto la de origen extranjero, que por los más diferentes motivos se internó en México con carácter temporal o definitivo, como la de origen nacional que emigró hacia Estados Unidos acorde con diversos planes y programas puestos en marcha para regular este flujo migratorio. De tal suerte que la inmigración y la emigración conforman los dos grandes universos documentales contenidos en este archivo.

Un segmento significativo de éste resguarda la documentación de millares de migrantes extranjeros y nacionales que iniciaron trámites para los más diversos objetivos: radicación, emigración, repatriación, naturalización, permisos diversos, etc. Pero además, existen abundantes documentos que se refieren a una diversidad de temas vinculados con acciones gubernamentales interesadas en ordenar los flujos migratorios que llegay normas, ordenanzas y circulares sobre diversos asuntos de la migración en México, junto con expedientes que informan sobre una construcción institucional que puede rastrearse en las discusiones de comisiones asesoras y en papeles que relatan los problemas a que se enfrentaron las autoridades migratorias en el cumplimiento de sus responsabilidades.

\section{HACIA UNA AGENDA DE INVESTIGACIÓN}

Cada una de las series documentales se refiere a acciones gubernamentales instituidas por las distintas legislaciones que rigieron la política de población en México. El AHINM da cuenta de estas acciones que, emprendidas desde 1926, complementaron o replantearon normas poblacionales puestas en marcha en los últimos años del Porfiriato.

\footnotetext{
${ }^{18}$ Véase el Apéndice de este artículo.
}

Ante una escasa población distribuida de manera desigual en un extenso territorio, el triunfante liberalismo de la segunda mitad del siglo XIX apostó por una política de puertas abiertas a la inmigración. Una diversidad de decretos y leyes intentaron hacer realidad el sueño de reforzar la población local con caudalosos aportes de extranjeros que podían incorporarse a la vida nacional de forma individual, pero también por medio de proyectos de colonización diseñados para ocupar espacios de la geografía mexicana donde la falta de habitantes se combinaba con una débil actividad económica. La presencia extranjera durante el último tercio del siglo XIX fue promovida para poblar, pero también para movilizar las potencialidades de abundantes riquezas naturales. En este contexto se ubican los esfuerzos colonizadores de algunas comunidades de italianos y franceses, pero también la llegada de una fuerte corriente de migrantes chinos y, en menor medida, japoneses, atraídos por una demanda de trabajo manual, sobre todo en los estados noroccidentales de la República. Las disposiciones que se dictaron en la época no estipulaban los requisitos ni los mecanismos para el ingreso de los extranjeros, y semejante apertura pronto enfrentó problemas que requirieron la atención de las autoridades. Uno de ellos fue de naturaleza sanitaria, debido a que inmigrantes de origen asiático fueron portadores de enfermedades infecciosas que no tardaron en causar alarma.

Un notable incremento en la llegada de extranjeros obligó al gobierno de Porfirio Díaz a promulgar la primera Ley de Inmigración en diciembre de 1908. En ella se reafirmó la convicción de que la afluencia de extranjeros era no sólo necesaria, sino deseable, como un medio para aliviar la escasez de brazos que afectaba a la nación. Esta ley instituía criterios de marcado liberalismo en la política migratoria, tales como la completa "igualdad de todos los países y de todas las razas, no estableciendo un solo precepto especial para ciudadanos de alguna nación, ni para los individuos de raza determinada". Sin embargo, anunciaba la necesidad de "defender nuestra salubridad, tanto en el orden material cuanto en el moral" 19 .

\footnotetext{
19 “Ley de Inmigración de 1908”, en Compilación histórica de la legisla-
} ción migratoria en México: 1821-2000, 2000: 109. 


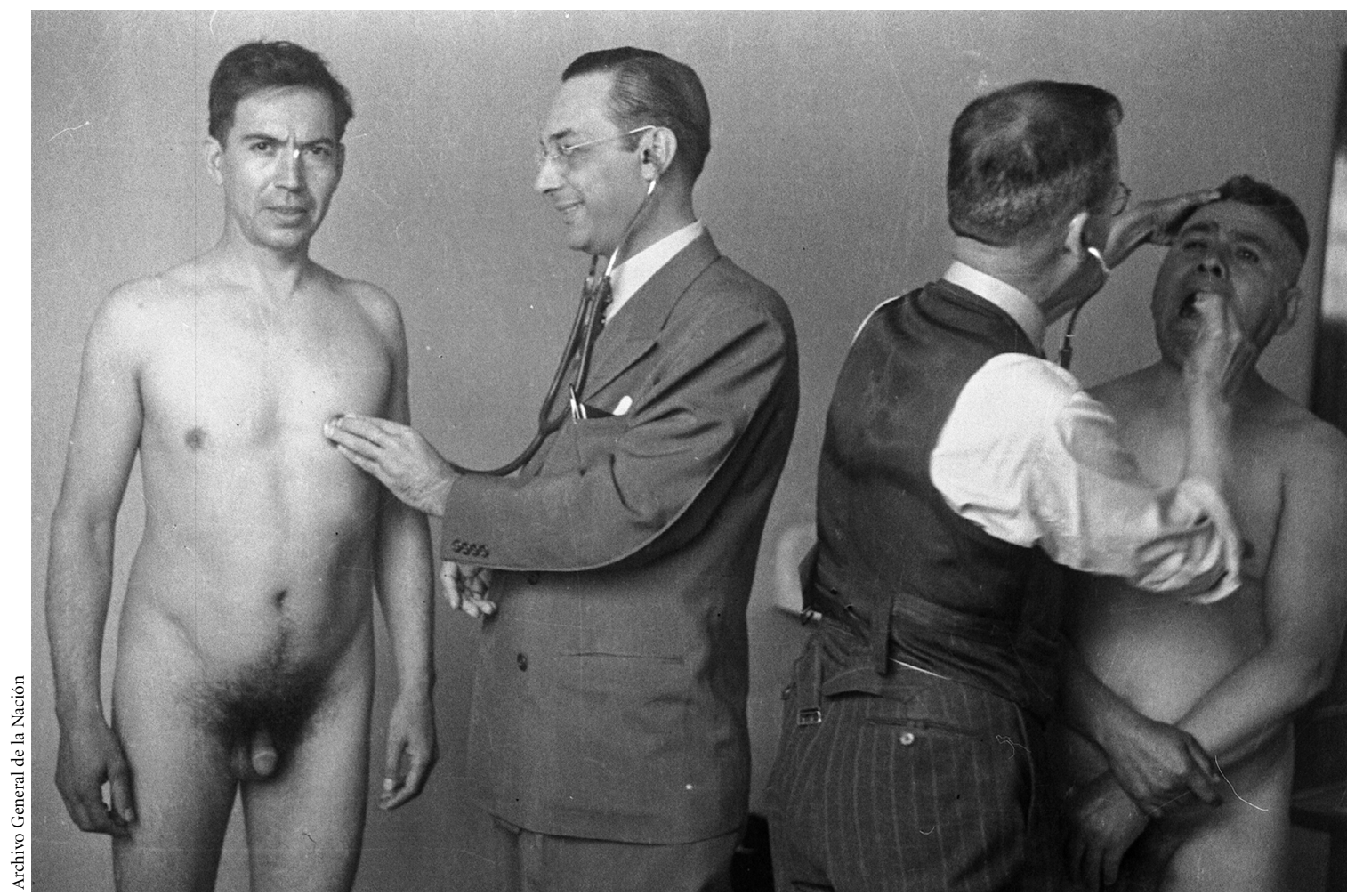

Examen médico, Estadio Nacional, México, D.F., 1943. Sección concentrada, “Braceros”, AGN.

Para esto quedaron establecidos los primeros requisitos que debía cumplir todo extranjero interesado en afincarse en México. De acuerdo con el artículo $3^{\circ}$, quedaba prohibido el ingreso al territorio nacional a:

I. Los enfermos de peste bubónica, cólera, fiebre amarilla, meningitis cerebro-espinal, fiebre tifoidea, tifo exantemático, erisipela, sarampión, escarlatina, viruela, difteria, o de cualquier otra enfermedad aguda que deba considerarse transmisible, en virtud de declaración del Ejecutivo; II) los enfermos de tuberculosis, lepra, beri-beri, tracoma, sarna egipcia, o de cualquier otra enfermedad crónica que deba considerarse transmisible, en virtud de declaración del Ejecutivo; III) los epilépticos y los que padecen enajenación mental; IV) los que, por ancianos, raquíticos, deformes, cojos, mancos, jorobados, paralíticos, ciegos, o de otro modo lisiados, o por cualesquiera defectos físicos o mentales, sean inútiles para el trabajo y hayan de convertirse en una carga para la sociedad; V) los niños menores de dieciséis años que no vengan bajo dependencia de otro pasajero no consignados a personas residentes en el país y que haya de tomarlos a su cargo; VI) los prófugos de la justicia y los que hubieren sido condenados por delito que, conforme a las leyes mexicanas, debiera castigarse con pena corporal de más de dos años, con excepción, para unos y otros de los delitos políticos o meramente militares; VII) los que pertenezcan a sociedades anarquistas, o que propaguen, sostengan o profesen la doctrina de la destrucción violenta de los gobiernos o el asesinato de funcionarios públicos; VIII) los mendigos y personas que de cualquier modo vivan de la caridad pública; IX) las prostitutas y los individuos que intenten introducirlas en el país para comerciar con ellas o vivir a sus expensas ${ }^{20}$.

Tales requisitos mostraron una extendida vigencia, ya que casi en su mayoría fueron incorporados a las subsecuentes legislaciones migratorias hasta promediar el siglo

\footnotetext{
${ }^{20}$ Ibid., 2000: 111-112.
} 


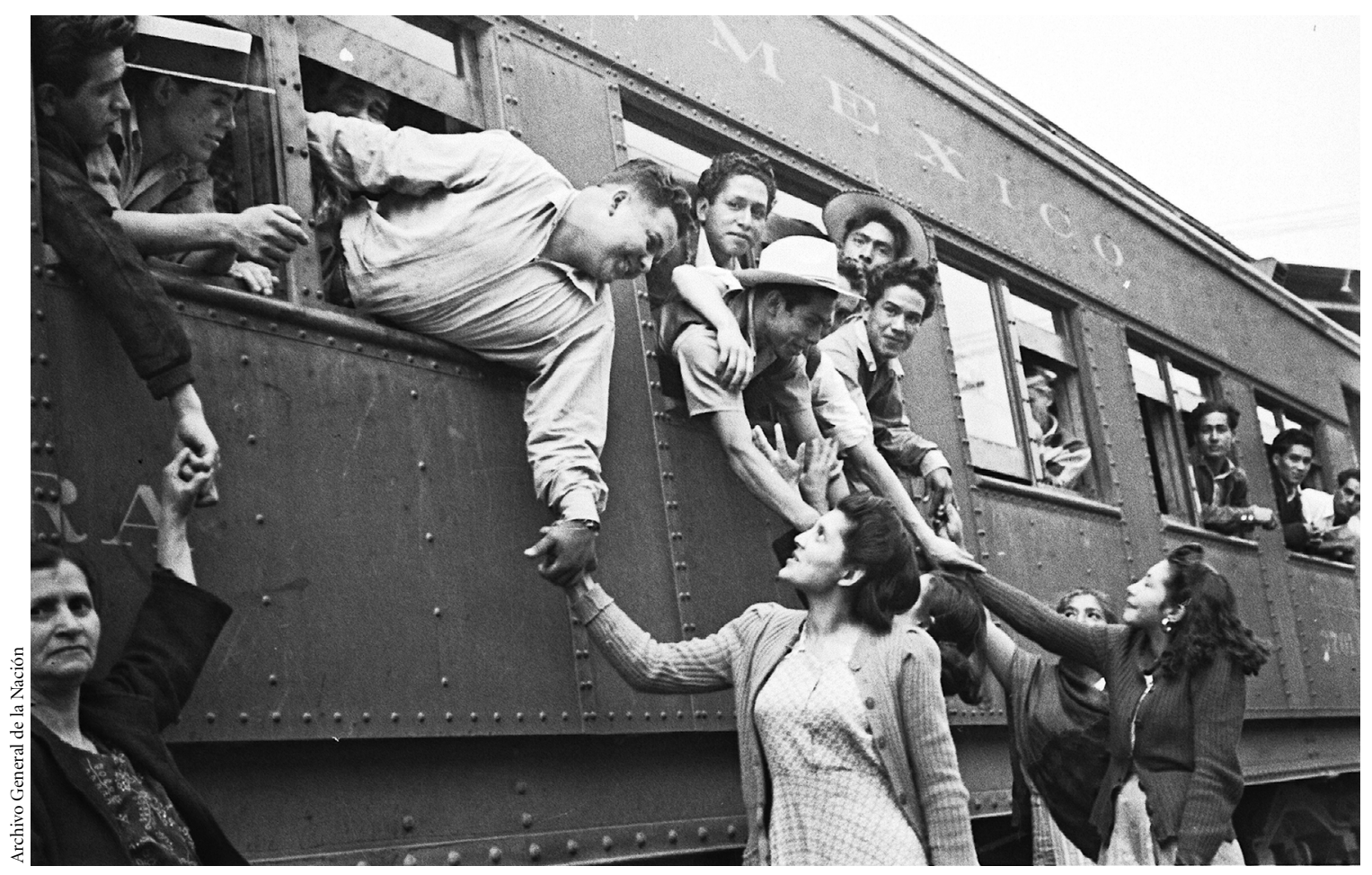

Estación de ferrocarril Buenavista, México, D.F., c. 1945. Sección concentrada, “Braceros”, AGN.

pasado. Sobre estas cuestiones, con particular énfasis en las restricciones y los informes sanitarios, el AHINM cuenta con nutrida documentación a lo largo de las siguientes series temáticas: 4/100(015), 4/350, 4/350.9, 4/ 360 y $4 / 360.1$.

La Ley de 1908, vigente durante casi dos décadas, instauró el primer cuerpo de inspectores migratorios, quienes junto con agentes auxiliares en los puertos y puntos fronterizos, se convirtieron en las autoridades facultadas para admitir, rechazar o expulsar a los extranjeros, así como para imponer penas administrativas. Sobre estos asuntos es abundante la información agrupada en las series $4 / 350.8,4 / 350.9,4 / 358$.

Una vez concluida la etapa armada de la Revolución, comenzó a modificarse el paradigma decimonónico que rigió la política migratoria. Por una parte, a escala mundial y a la luz de los enormes desplazamientos humanos verificados en las últimas décadas del siglo XIX, se inició un cuestionamiento de los beneficios que reportaría una afluencia masiva de extranjeros, de suerte que países con una larga tradición inmigratoria como Estados Unidos, Argentina, Australia y Canadá iniciaron movimientos tendientes a controlar y seleccionar a los inmigrantes. México, aunque en menor proporción, compartió estos problemas, pero además lo hizo en la particular etapa que inauguró la Constitución Política de 1917.

La legislación revolucionaria atendió con especial cuidado los derechos de los trabajadores mexicanos como una respuesta a las difíciles condiciones de vida de obreros y campesinos, pero también como una protección ante los privilegios de que gozaron los extranjeros durante la prolongada dictadura de Porfirio Díaz. En este contexto, los gobiernos revolucionarios asumieron el compromiso de proteger a los connacionales que abandonaban el país por cuestiones laborales. Esta preocupación quedó plasmada en el artículo $123^{\circ}$ de la Constitución, que estableció que los contratos de trabajo celebrados entre mexicanos y empresarios extranjeros debían especificar 
claramente que los gastos de repatriación correrían por cuenta del empleador. Esta novedad en materia de emigración se combinó con una coyuntura en la que México comenzó a resentir la deportación masiva de trabajadores mexicanos desde Estados Unidos, como consecuencia de las cíclicas crisis en la economía de la nación vecina. Así, la política migratoria de la Revolución empezó a mostrar perfiles más restrictivos y a abandonar los muy liberales criterios que la caracterizaron durante un siglo.

Al gobierno de Plutarco Elías Calles correspondió la aprobación de la primera Ley de Migración sancionada por la Revolución. Promulgada en marzo de 1926, contempló las dos caras del fenómeno migratorio: la entrada de extranjeros y la salida de mexicanos. Para estos últimos se estableció la categoría de emigrante y para los extranjeros se establecieron las categorías de inmigrante, con una novedad: la tarjeta de turista, para distinguir a aquellos extranjeros que estaban de paso de los que venían para radicarse en la República.

En materia de inmigración se incorporaron algunas restricciones para el ingreso, como saber leer y escribir, la prohibición de entrada para los toxicómanos y los traficantes ilegales de drogas enervantes. Por otra parte, para los inmigrantes trabajadores quedó establecido el requisito de exhibir un contrato de trabajo al momento de entrar al país o, en su defecto, demostrar que contaban con los recursos suficientes para llegar a su lugar de destino y cubrir los gastos individuales y familiares durante tres meses a partir de la fecha de internación. Pero aún más importante, la nueva ley autorizaba a la Secretaría de Gobernación para que, cuando existiera escasez de trabajo en la República, prohibiera temporalmente la entrada de trabajadores de origen extranjero ${ }^{21}$.

En materia de emigración, se facultó a la Secretaría de Gobernación para dictar las medidas necesarias a fin de impedir la salida de los nacionales que no cumplieran con las leyes del país de destino, con la esperanza de evitar así nuevas oleadas de repatriados. A los trabajadores mexicanos, conforme el espíritu de la Carta Magna,

${ }^{21}$ Artículo 65 de la "Ley de Migración de 1926", Diario Oficial de la Federación, 13 de marzo de 1926, México-Distrito Federal, pp. 1-8. se les impuso la obligación de presentar una copia del contrato celebrado con empresarios extranjeros. Con la idea de hacer aún más específicos estos requisitos, en las leyes migratorias subsecuentes se definió que esos contratos debían tener una vigencia mínima de seis meses, estableciendo que los gastos de transporte y alimentación serían cubiertos por el empleador, quien además debía depositar o pagar una fianza que garantizara la repatriación. A pesar de las buenas intensiones que animaban estos requerimientos, el problema de la emigración estuvo muy lejos de resolverse; por el contrario, el incumplimiento de estas normas no hizo más que alimentar el tráfico ilegal de mexicanos en la frontera norte. El AHINM cuenta, en su serie 4/357.1, con millares de contratos de trabajo que permitirían reconstruir el perfil de los mexicanos que abandonaron el país entre mediados de la década de 1920 y de la de 1960. Complementan estos documentos informes consulares y quejas de particulares que exhiben las constantes violaciones de los convenios laborales.

Desde la ley migratoria de 1926 fue evidente la preocupación por vigilar el tránsito de personas a lo largo de las fronteras, pero también la necesidad de ordenar y controlar la presencia de extranjeros en el país. En atención a esas preocupaciones quedó instituida la expedición de una tarjeta de identificación para todos los que entraban o salían del territorio nacional. Los extranjeros que ya vivían en la República debían tramitar este documento ante las autoridades municipales, mientras que los nuevos inmigrantes debían hacerlo en el consulado mexicano en su lugar de residencia o de embarque. Por su parte, los emigrantes quedaron obligados a gestionar sus tarjetas en las estaciones migratorias localizadas sobre todo en las líneas de frontera. De manera complementaria se estableció el Registro de Nacionales y Extranjeros, al tiempo que se inauguró la práctica — que continúa hasta nuestros días - tendiente a la elaboración de estadísticas sobre el movimiento en puertos y fronteras. Entre otras, las series 4/020, 4/350.1(08), 4/ 350.1(015), 4/350.3, 4/350.5 contienen información sobre estos asuntos.

Al concluir la década de 1920 fueron puestas las bases de un sistema nacional de migración. La Secretaría de Gobernación envió visitadores a recorrer las distintas dele- 
gaciones con el objeto de evaluar su funcionamiento y reportar las anomalías y carencias. Es así que a partir de aquellos años contamos con reportes detallados de estos empleados itinerantes, que aportan información sobre la naturaleza de sus tareas y las dificultades para poner en práctica las nuevas disposiciones (serie 4/161).

La crisis internacional de 1929 forzó a millares de mexicanos a regresar al país. El gobierno tuvo que hacer frente a la situación sin contar con las herramientas legales e institucionales necesarias. Correspondió al Departamento Migratorio coordinar este esfuerzo en colaboración con otras secretarías de Estado. Hacia 1929, y de cara a una situación inusitada en materia migratoria, el Departamento de Migración convocó a una Convención de Delegados de Migración para atender los problemas derivados del ingreso de nuevos inmigrantes y el regreso de Estados Unidos de millares de mexicanos. Estos problemas obligaron a delinear una nueva ley que se promulgó en agosto de 1930.

Esta nueva ley redefinió, en primer lugar, las funciones del Departamento Central y de las oficinas ubicadas en distintas poblaciones en el interior del país, en los puertos y las fronteras e inclusive en el extranjero; en segundo lugar, creó el Consejo Consultivo de Migración. Este organismo, integrado por representantes de distintas secretarías de Estado, además de académicos y profesionales en el estudio de los problemas demográficos, atendió cuestiones derivadas del funcionamiento del Servicio Migratorio y de la aplicación de la legislación vigente. Entre muchas cuestiones, asesoró en políticas para el fomento de una inmigración adecuada, en propuestas para la solución de los problemas derivados de la repatriación de mexicanos y en acciones de colonización e impulso al turismo. El AHINM, en su serie 4/350, guarda una buena colección de las Actas de Sesiones de este Consejo Consultivo; entre esta documentación destacan las propuestas que ciudadanos y organizaciones políticas preocupadas por los problemas migratorios que enfrentaba el país hicieron a las autoridades.

En materia de inmigración, la nueva legislación resultó más restrictiva. Entre los requisitos de ingreso se incorporó la categoría de "elementos asimilables", es decir, se invocó a la mayor o menor capacidad para incorpo- rarse a la vida y costumbres de la nación, lo que determinaría el grado de beneficio que una comunidad de extranjeros reportaría al país. Por otra parte, y de cara a un mercado laboral cada vez más estrecho, las autoridades migratorias prohibieron la inmigración temporal de trabajadores. La resolución fue firmada en julio de 1931 y sentó un precedente de gran influencia a lo largo de toda esa década.

La nueva legislación también facultó a la Secretaría de Gobernación para restringir e incluso prohibir la salida de nacionales cuando se registrara "una sensible despoblación en el territorio nacional o en una parte del mismo"22. Para ello, las oficinas ubicadas en los distintos estados debían investigar las causas regionales de la emigración, su previsión y su remedio. Por otro lado, el Estado, a través de esta nueva normatividad, asumió el compromiso de facilitar la repatriación de aquellos mexicanos que se encontraran en condiciones de indigencia o enfermedad, o cuando el país, "por necesidad de braceros, estuviera en posibilidades de ofrecerles oportunidades ventajosas"23. Las peticiones de los connacionales que deseaban regresar al país se encuentran en las series 4/356 y $4 / 357.1$.

El nacionalismo revolucionario presente en ideas y acciones gubernamentales subyace en los intentos por regular e inclusive prohibir la salida de mexicanos. Se intentaba proteger a una mano de obra que sería sometida a condiciones de trabajo violatoria de derechos vigentes en México y que, llegado el caso, sería dejada a su suerte sin posibilidad de contar con los recursos necesarios para regresar a México. Las autoridades mexicanas, con el deseo de gestar condiciones que evitaran la emigración, no siempre vieron sus esfuerzos coronados con el éxito, e inclusive, en la mayoría de los casos, la pobreza presupuestal impidió que las solicitudes de repatriación fueran atendidas de manera expedita. Las fuentes que dan cuenta de este proceso, sus actores y sus acciones forman parte del acervo del AHINM.

\footnotetext{
22 Artículo $152^{\circ}$ del "Reglamento de la Ley de Migración", Diario Oficial de la Federación, 14 de junio de 1932, Segunda Sección, MéxicoDistrito Federal, pp. 1-36.

23 Artículo $160^{\circ}$ del "Reglamento de la Ley de Migración", ibid.
} 


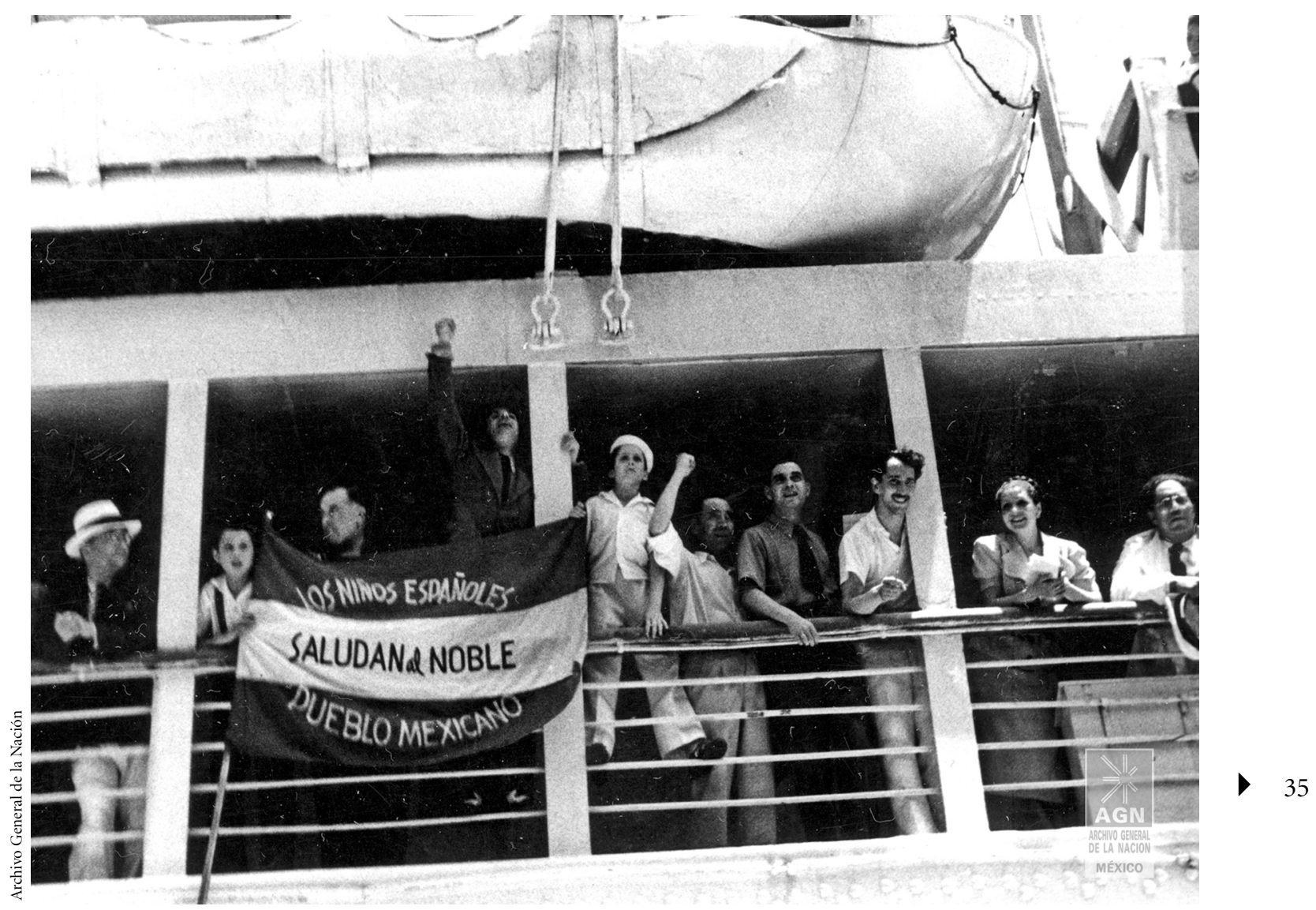

Arribo del Mexique 2 con niños refugiados españoles, 7 de junio de 1937. Archivo fotográfico Enrique Díaz, Delgado y García, AGN.

Las difíciles condiciones por las que atravesó México durante los primeros años de la década de 1930 obligaron a limitar aún más la política migratoria. Esta situación se hizo explícita en la Ley General de Población promulgada en agosto de 1936. A diferencia de las precedentes, esta nueva legislación significó un parteaguas en la historia de la política poblacional. México hizo explícito el abandono de una estrategia para incrementar su población basada exclusivamente en el ingreso de extranjeros, para reemplazarla por una apuesta al incremento natural de la población, acompañada por un reordenamiento de los grupos de repatriados y por una inmigración firmemente controlada. Sobre la base de un nuevo diagnóstico demográfico, se perfilaron políticas de población fundadas en los siguientes puntos:
I) El aumento de la población: crecimiento natural, repatriación, inmigración; II) su racional distribución dentro del territorio; III) la fusión étnica de los grupos nacionales entre sí; IV) el acrecentamiento del mestizaje nacional mediante la asimilación de los elementos extranjeros; V) la protección de los nacionales en sus actividades económicas, profesionales, artísticas o intelectuales, mediante disposiciones migratorias; VI) la preparación de los núcleos indígenas para constituir mejor aporte físico, económico y social desde el punto de vista demográfico; VII) la protección general, conservación y mejoramiento de la especie, dentro de las limitaciones y mediante los procedimientos que señala esta Ley ${ }^{24}$.

${ }^{24}$ Artículo $1^{\circ}$ de la "Ley General de Población de 1936", Diario Oficial de la Federación, 29 de agosto de 1936, México-Distrito Federal, pp. 1-14. 


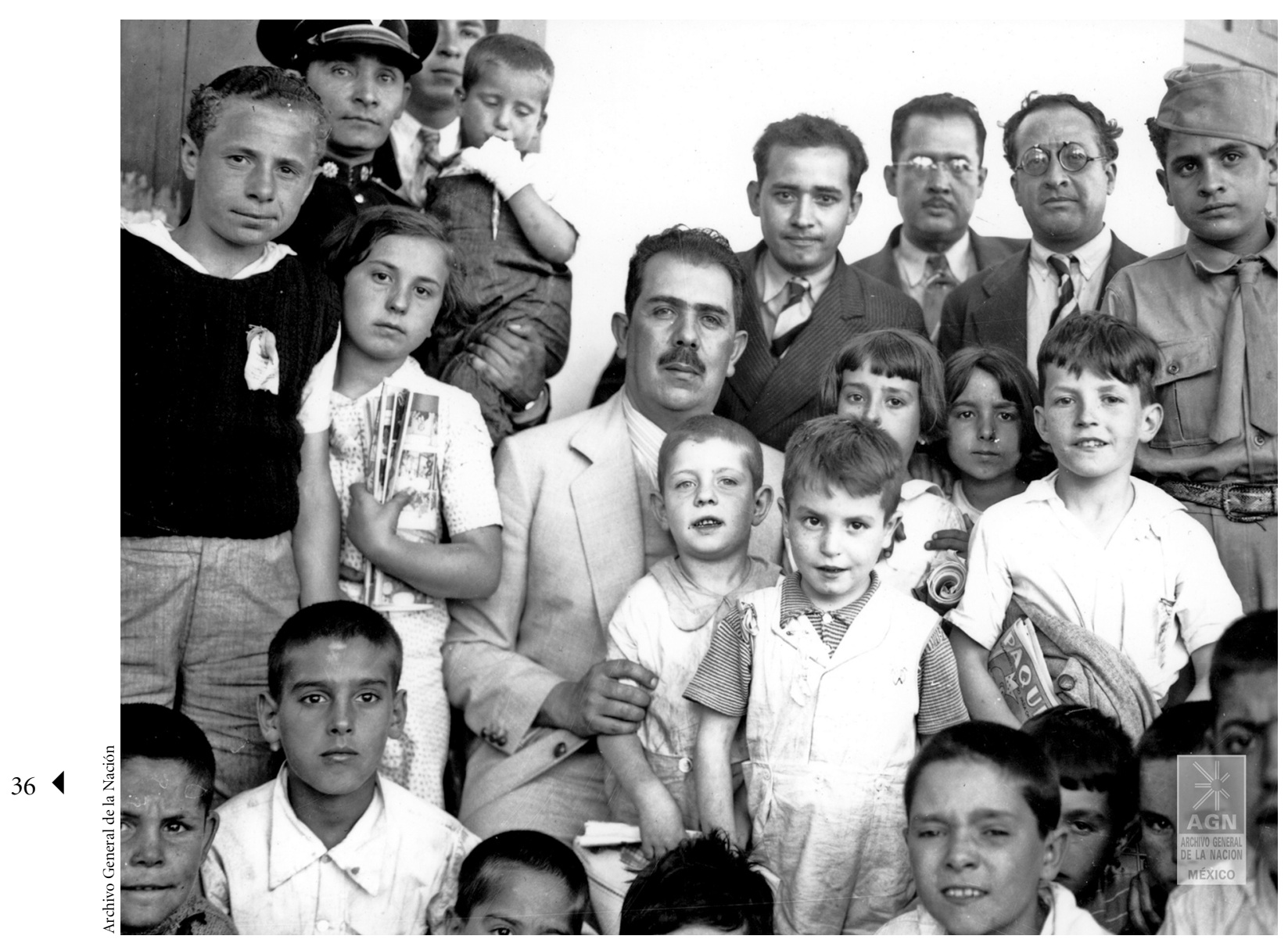

Los niños refugiados españoles y el presidente Lázaro Cárdenas, 1937. Archivo fotográfico Enrique Díaz, Delgado y García, AGN.

La puesta en práctica de políticas tendientes a la atención de estos problemas hizo más compleja la organización y el funcionamiento del Departamento Migratorio, y en materia inmigratoria obligó a establecer nuevas especificaciones en los procesos de documentación de los extranjeros. Por primera vez se estableció una diferencia entre inmigrantes e inmigrados. Los primeros fueron todos aquellos que ingresaban al país con el propósito de radicar y con la autorización de ejercer actividades remuneradas o lucrativas. La segunda categoría estaba formada por aquellos extranjeros que, después de cinco años de residencia consecutiva, adquirían el derecho de estancia definitiva. Se reconocía, además, la condición de turista, transmigrante y visitante, que en las leyes subsecuentes quedaron integradas en la categoría de "no inmigrante". Con las fuentes conservadas en el Archivo, estas distinciones administrativas permitirían vigilar las especificidades del mercado laboral donde se insertaron los extranjeros, sus ramas de actividades, localización geográfica, salarios y empresas que crearon o en las que se emplearon. Por otra parte, los registros sobre el ingreso y egreso de turistas ponen a disposición del investigador una fuente para trabajar sobre una actividad escasamente estudiada en su dimensión histórica.

Los agudos problemas que en materia laboral enfrentó el país salieron al encuentro de un discurso nacionalista profundamente receloso de intereses y acciones de empresas y empresarios extranjeros, al punto que ese dis- 
curso moldeó una política inmigratoria con un marcado sesgo restrictivo. Por ejemplo, se prohibió a los extranjeros el ejercicio de profesiones liberales, se limitaron emprendimientos comerciales o industriales que podían desarrollar los inmigrantes, se restringió el ejercicio sistemático y remunerado de actividades intelectuales o artísticas. Por tiempo indefinido quedó prohibida la entrada al país de inmigrantes trabajadores y se sujetó la admisión de técnicos a los dictámenes que sobre este asunto emitiera el Consejo Consultivo de Población. Con la idea de proteger el mercado laboral, la autoridad migratoria creó la Sección de Revisión de Antecedentes, instancia encargada de reforzar la vigilancia sobre el tipo de actividades laborales desarrollada por los extranjeros y evitar violaciones a la legislación vigente. Todo ello en el marco del establecimiento de las llamadas "Tablas Diferenciales", que desde finales de 1937 fijaron las cuotas anuales de extranjeros que serían admitidos, dependiendo de sus naciones de origen. El archivo contiene una buena cantidad de documentos relacionados con estas limitaciones, que pueden consultarse en la serie 4/350.

Es importante destacar que, a pesar de todas estas restricciones, a partir de 1936 la legislación migratoria mexicana incorporó los casos de aquellos extranjeros que ingresaban al país por razones de persecución política. El archivo resguarda una abultada serie de "refugiados" (4/ 351.8) en la que se conservan los expedientes de los asilados que se asentaron en el país, desde el republicano español a finales de la década de 1930 hasta los exiliados latinoamericanos que llegaron en la década de 1960. Esta serie se significa como una fuente extraordinaria para explorar las dimensiones cuantitativas de las comunidades de refugiados políticos.

La legislación poblacional cardenista estipuló que la repatriación debía ser un esfuerzo sistemático del gobierno nacional; para ello estableció el estudio de las condiciones tanto de los mexicanos en el extranjero como de las regiones del país en posibilidad de recibirlos, y emprender así una intensa campaña propagandística para promover el regreso. En un momento en que el gobierno profundizaba el reparto agrario, la política de repatriación contempló la dotación de tierras, maquinarias y herramientas de trabajo para el establecimiento de las colonias de agricultores y trabajadores industriales, a quienes, por cierto, se les autorizó a introducir, libres de derechos, los enseres necesarios para el desempeño de sus labores. Estas propuestas fueron motivo de estudio y de proyectos que pueden consultarse en los documentos en el AHINM ${ }^{25}$.

La Segunda Guerra Mundial modificó las condiciones de la migración internacional, dado que una gran movilización de desplazados por la conflagración presionó sobre las políticas migratorias en distintos países. Pero además, el ingreso de Estados Unidos al conflicto bélico elevó la demanda de mano de obra para ocupar los puestos que dejó vacantes el reclutamiento militar. Por primera vez, para México se abrió la posibilidad de diseñar un plan para regular la migración hacia la nación vecina y, como consecuencia, al descomprimirse el problema de la repatriación se pudieron liberar recursos para atender otras áreas del Departamento Migratorio.

En 1942 los gobiernos de México y de Estados Unidos firmaron dos convenios laborales — uno para trabajadores agrícolas y otro para empleados ferroviarios- que inicialmente estarían en vigor hasta el fin de la guerra. Sin embargo, el primero de los acuerdos se prorrogó hasta 1964. Al calor del llamado "Programa Bracero" salieron del país cerca de cinco millones de mexicanos; sobre este asunto hay una variada documentación en el archivo, entre la que destacan las cartas de los ciudadanos que solicitaban su registro e inclusión en el Programa. Estos expedientes exhiben el perfil y las motivaciones que los orillaron a abandonar el país, pero también echan luz sobre los orígenes de un fenómeno de actualidad: el tráfico ilegal, toda vez que los solicitantes rechazados alimentaron los flujos clandestinos a lo largo de la frontera ${ }^{26}$.

Estas nuevas condiciones para los emigrantes no tuvieron un correlato en materia de inmigración. Los gobiernos mexicanos no flexibilizaron las regulaciones a las que estuvo sometida la población extranjera que deseaba radicar en México. Si bien el régimen de "Tablas Diferenciales" fue eliminado en 1946, la nueva Ley General de Población promulgada en 1947 reprodujo el conjunto de

\footnotetext{
${ }^{25}$ Series 4/122.1, 4/123.1, 4/123.2, 4/350, 4/356 y 4/357.1.

${ }^{26}$ Series $4 / 161,4 / 350,4 / 357.1$ y $4 / 358$.
} 
restricciones laborales que había establecido la legislación anterior. El artículo $48^{\circ}$ de la nueva Ley General de Población detalló las actividades para las que se autorizaría el ingreso de extranjeros en calidad de inmigrantes:

I) Para disfrutar de sus rentas, pensiones, depósitos, cuentas bancarias o cualquier otro ingreso permanente y lícito; II) para invertir su capital en cualquier ramo de la industria, la agricultura o el comercio de exportación, en forma estable y distinta a la de sociedades por acciones; III) para invertir su capital en certificados, títulos o bonos del Estado o de las instituciones nacionales de crédito, en la forma y términos que determine la Secretaría de Gobernación; IV) los profesionistas, en casos excepcionales y de acuerdo con las leyes vigentes en materia; V) para asumir la administración u otro cargo de responsabilidad y absoluta confianza al servicio de empresas o instituciones establecidas en la Republica, siempre que a juicio de la Secretaría no exista duplicidad de cargos y que el servicio de que se trate amerite la internación; VI) para prestar servicios técnicos o especializados que no puedan ser prestados, a juicio de la Secretaría, por residentes en el país; VII) para iniciar, completar o perfeccionar sus estudios en planteles educativos oficiales o particulares incorporados; VIII) para vivir bajo sanguíneo dentro del tercer grado, inmigrante, inmigrado o mexicano $[\ldots]^{27}$.

El AHINM conserva la documentación de los trámites realizados por extranjeros en cada uno de los casos antes citados, así como de las más diversas gestiones que estaban obligados a realizar ante la autoridad migratoria. Un estudio cuidadoso de estas series documentales, que llegan hasta la década de 1960, permitiría hacer una radiografía de la evolución de las características sociodemográficas de las comunidades de inmigrantes radicadas en el país.

En conclusión, el acervo del AHINM remite a la documentación generada por el primer Departamento Migratorio de la Secretaría de Gobernación y, en tal sentido, desde el punto de vista histórico, los fondos rescatados constituyen la materia prima para una reconstrucción

27 Artículo $48^{\circ}$ de la "Ley General de Población de 1947”, Diario Oficial de la Federación, 27 de diciembre de 1947, México-Distrito Federal, pp. 3-10.

atenta a los orígenes y desenvolvimientos de la política de población mexicana durante buena parte del siglo XX. Con la información que contienen algunas de las series documentales será posible rastrear las discusiones, los proyectos y una diversidad de posiciones de funcionarios $\mathrm{y}$ equipos gubernamentales en determinadas coyunturas de la historia nacional, en las cuales fueron promulgadas leyes, decretos y normas legales para regular el ingreso y la presencia de inmigrantes en México, pero también para regular y ordenar el tráfico de emigrantes y de repatriados. Es decir, la información que atesora este archivo permitirá redimensionar los estudios sobre los flujos migratorios desde y hacia México. Con bastante precisión se podrá calibrar el flujo y el perfil de la inmigración, así como los cambios registrados en las comunidades de inmigrantes a lo largo de su residencia en el país. Será posible conocer segmentos de la corriente emigratoria, aquella realizada bajo supervisión estatal. Se arrojará luz sobre asuntos hoy ignorados, como el caso del funcionamiento de las redes familiares que alentaron procesos de inmigración y emigración, así como la labor de instancias gubernamentales para controlar y ordenar a emigrantes e inmigrantes. En resumen, cuando este archivo se abra a la consulta académica, dará comienzo una nueva etapa en el estudio de los procesos migratorios en México, toda vez que será posible desarrollar investigaciones cuantitativas y cualitativas sobre un pasado en buena medida desconocido. Un pasado que, por cierto, no ha dejado de nutrir los problemas de un presente atravesado por el desafío de administrar incesantes y cada vez mayores movimientos internacionales de población.

\section{Bibliografía}

Alanis Enciso, Fernando Saúl, 2007, Que se queden allá. El gobierno de México y la repatriación de mexicanos de Estados Unidos, 1934-1940, El Colegio de San Luis Potosí, El Colegio de la Frontera Norte, México.

Backal, Alicia G. de, 1993, Generaciones judías en México. La Kehilá Ashkenazi, 1922-1992, 7 vols., Comunidad Ashkenazí de México, México.

Balderrama, Francisco y Raymond Gutierrez, 1995, Decade of Betrayal. Mexicans Repatrieted in the 1930's, University of New Mexico Press, Alburquerque, New Mexico. 
Bonfil Batalla, Guillermo (comp.), 1993, Simbiosis de culturas. Los inmigrantes y su cultura en México, Consejo Nacional para la Cultura y las Artes, Fondo de Cultura Económica, México.

Carreras de Velasco, Mercedes, 1974, Los mexicanos que devolvió la crisis, 1929-1932, Secretaría de Relaciones Exteriores, México.

Compilación histórica de la legislación migratoria en México: 1821-2000, 2000, Coordinación de Planeación e Investigación, Instituto Nacional de Migración, México.

Gamio, Manuel, 1969, El inmigrante mexicano: la historia de su vida, Universidad Nacional Autónoma de México, México.

Gleizer Salzman, Daniela, 2000, México frente a la inmigración de refugiados judíos, 1934-1940, Instituto Nacional de Antropología e Historia, Fundación Cultura Eduardo Cohen, México.

Gómez Izquierdo, José Jorge, 1991, El movimiento antichino en México, 1871-1934, Instituto Nacional de Antropología e Historia, México.

González Navarro, Moisés, 1954, "Braceros en el Porfiriato", en Estudios sociológicos. Sociología económica, t. II, Instituto de Investigaciones Sociales, Universidad Nacional Autónoma de México, México.

, 1974, Población y sociedad (1900-1972), Universidad Nacional Autónoma de México, México.

__, 1993-1994, Los extranjeros en México y los mexicanos en el extranjero, 3 ts., El Colegio de México, México.
Guerin-González, Camilla, 1994, Mexican Workers and American Dream. Inmigration, Repatriation and California Farm Labor, 1900-1939, Rutgers University Press, New Brunswick.

Hu-Dehart, Evelyn, 1980, "Inmigration to a Developing Society. The Chinese in Nothern Mexico, 1875-1932", Journal of Arizona History, pp. 21-48.

Lida, Clara, 2006, "Los españoles en el México independiente, 1821-1950. Un estado de la cuestión”, Historia Mexicana, núm. 221 (vol. LVI, núm. 2), julio-septiembre.

Páes Oropeza, Carmen Mercedes, 1984, Los libaneses en México: asimilación de un grupo étnico, Instituto Nacional de Antropología e Historia, México.

Pérez Siller, Javier y Chantal Cramaussel (coords.), 2004, México, Francia: memoria de una sensibilidad común, siglos XIX-XX, Benemérita Universidad Autónoma de Puebla, El Colegio de Michoacán, Centro de Estudios Mexicanos y Centroamericanos, México.

Puig Llano, Juan, 1992, Entre el río Perla y el Nazas: la China decimonónica y sus braceros emigrantes, la colonia china de Torreón y la matanza de 1911, Consejo Nacional para la Cultura y las Artes, México.

Salazar, Delia, 2006, Xenofilia y xenofobia en la historia de México, Instituto Nacional de Migración, Instituto Nacional de Antropología e Historia, México.

Apéndice. Series temáticas del Archivo Histórico del Instituto Nacional de Migración

\begin{tabular}{l|l}
\hline Serie & Tema \\
\hline 000 & Asignación de personal \\
\hline 002 & Juicios de amparo de extranjeros \\
\hline 009 & Desórdenes Públicos \\
\hline 010 & Solicitudes de informes sobre extranjeros \\
\hline 010.1 & Solicitudes de localización de extranjeros \\
\hline 010.2 & Situación migratoria de extranjeros \\
\hline 013.3 & Extranjeros acusados de estafa y/o peculado \\
\hline 013.6 & Falsificación de documentos \\
\hline 013.7 & Contrabando \\
\hline 013.8 & Suplantación de empleo en servicio migratorio \\
\hline 013.9 & Irregularidades cometidas por empleados migratorios \\
\hline
\end{tabular}




\begin{tabular}{|c|c|}
\hline Serie & Tema \\
\hline 020 & Aduanas, fronteras, viajeros en tránsito y permisos especiales \\
\hline 021 & Facilidades otorgadas en el aeropuerto \\
\hline 090 & Circulares sobre extranjeros expulsados \\
\hline 090.2 & Solicitud de ejemplares de leyes, reglamentos, informes \\
\hline 090.4 & Informes y memorias del Departamento de Migración \\
\hline 091.1 & Solicitud de ejemplares de Ley de Migración \\
\hline 091.3 & Órdenes de impresión \\
\hline 091.4 & Órdenes de encuadernación \\
\hline 091.5 & Recortes de prensa \\
\hline 099.1 & Acuses de recibo \\
\hline 100 & Asuntos internos del Departamento de Migración \\
\hline $100(02)$ & Personal del Departamento de Migración \\
\hline $100(03)$ & Necesidades del Departamento de Migración \\
\hline $100(04)$ & Informes internos del Departamento de Migración \\
\hline $100(05)$ & Informes sobre planos y maquetas \\
\hline 100(07) & Correspondencia entre Agencias y Delegaciones \\
\hline $100(015)$ & Circulares a delegados y agentes de migración \\
\hline $100(016)$ & Circulares y acuerdos de la Secretaría de Gobernación \\
\hline 122 & Reclamos al Departamento de Migración por adeudos \\
\hline 122.1 & Fianzas y depósitos para repatriación \\
\hline 123 & Vales, pases y cortes de cuentas mensuales \\
\hline 123.1 & Solicitudes de pases y vales para empleados y repatriados \\
\hline 123.2 & Solicitud de pasajes para empleados y repatriados \\
\hline 124 & Mensajes dirigidos a los ciudadanos \\
\hline 127 & Cuentas mensuales de ingresos \\
\hline 127.1 & Correspondencia interna \\
\hline 127.3 & Servicios migratorios extraordinarios \\
\hline 128 & Gastos administrativos \\
\hline $128(07)$ & Comprobantes de gastos \\
\hline 128.1 & Nóminas del Departamento de Migración \\
\hline 128.2 & Sueldos de los funcionarios del Departamento de Migración \\
\hline 130 & Asignación de personal \\
\hline $130(04)$ & Asistencia del personal del Archivo de Migración \\
\hline 135 & Bajas del personal del Departamento de Migración \\
\hline
\end{tabular}




\begin{tabular}{|c|c|}
\hline Serie & Tema \\
\hline 161 & Visitas de Inspección \\
\hline 241 & Informes de fecha de internación de extranjeros \\
\hline 303 & Datos para informes presidenciales \\
\hline 334 & Disposiciones para nacionalización de extranjeros \\
\hline 340 & Ministros de culto \\
\hline 350 & Correspondencia interinstitucional \\
\hline 350.1 & Informes y movimientos migratorios \\
\hline $350.1(03)$ & Estadísticas migratorias \\
\hline $350.1(07)$ & Irregularidades en la expedición de documentos \\
\hline $350.1(08)$ & Estadísticas migratorias \\
\hline $350.1(015)$ & Expedición de tarjetas de identificación \\
\hline $350.1(73)$ & Migración americana \\
\hline 350.2 & Consultas y quejas sobre extranjeros indeseables \\
\hline $350.2(73)$ & Ingreso a Estados Unidos \\
\hline 350.3 & Tránsito internacional de puentes y garitas \\
\hline 350.4 & Solicitudes de internarse a Baja California \\
\hline 350.5 & Movimiento de barcos y aviones \\
\hline 350.6 & Tripulaciones en naves extranjeras \\
\hline 350.7 & Denuncias de extranjeros ilegales \\
\hline 350.8 & Multas por violación a Ley de Migración \\
\hline 350.9 & Extranjeros rechazados \\
\hline 350.61 & Tripulación desertora de naves extranjeras \\
\hline 350.62 & Regularización de calidad migratoria \\
\hline 351 & Visas y pasaportes \\
\hline 351.0 & Solicitudes de internación temporal \\
\hline 351.1 & Inmigrantes detenidos \\
\hline 351.2 & Inmigrantes temporales: trabajadores \\
\hline 351.3 & Avisos de actividades civiles de inmigrados \\
\hline 351.4 & Familiares de inmigrantes: estudiantes y menores de edad \\
\hline 351.5 & Inmigrantes temporales: Artistas \\
\hline 351.6 & Inmigrantes temporales: Deportistas \\
\hline 351.7 & Movimiento diplomático \\
\hline 351.8 & Refugiados y asilados políticos \\
\hline 351.9 & Inmigrantes temporales: Científicos adscritos a alguna institución \\
\hline
\end{tabular}




\begin{tabular}{|c|c|}
\hline Serie & Tema \\
\hline 351.9 .1 & Inmigrantes temporales: Científicos y hombres de negocios \\
\hline 351.13 & Tripulación extranjera \\
\hline 351.14 & Multas por violación a Ley de Migración \\
\hline 352 & Emigración \\
\hline 352.11 & Informes de movimiento migratorio en la República \\
\hline 352.12 & Solicitudes para que se impida la entrada o salida de extranjeros \\
\hline 353 & Solicitudes de visa \\
\hline 354.3 & Cambios de calidad migratoria \\
\hline 354.4 & Excursiones turísticas \\
\hline 354.6 & Internación \\
\hline 355 & Solicitudes de calidad de inmigrado \\
\hline 355.1 & Solicitud de documentos migratorios \\
\hline 355.2 & Solicitudes de certificados de legal internación/estancia en el país \\
\hline 356 & Repatriación \\
\hline 357 & Permisos de salida \\
\hline 357.0 & Solicitud de reingreso al país \\
\hline 357.1 & Emigración de trabajadores mexicanos \\
\hline 357.9 & Permisos especiales entrada y salida \\
\hline 358 & Deportaciones \\
\hline 360 & General de inmigración \\
\hline 360.1 & Solicitudes de internación e inmigración \\
\hline 360.2 & Extranjeros que ingresan como turistas y cambian de calidad \\
\hline 360.3 & Extranjeros pescadores y cazadores \\
\hline 360.4 & Movimiento de extranjeros al interior del país \\
\hline 360.5 & Solicitud de internación de sacerdotes \\
\hline 361 & Solicitudes de naturalización \\
\hline 362.1 & Solicitudes de expulsión \\
\hline 362.2 & Expulsiones \\
\hline 362.3 & Deportaciones y expulsiones \\
\hline 365 & Consultas sobre nacionalidad de extranjeros residentes \\
\hline 371 & Movimiento demográfico \\
\hline 411 & Autorización de rutas aéreas \\
\hline
\end{tabular}

